\title{
Characterization and intracellular localization of putative Chlamydia pneumoniae effector proteins
}

\author{
Nicole Müller · Florian Sattelmacher • \\ Raimond Lugert $\cdot$ Uwe Groß
}

Received: 6 December 2007 / Published online: 1 May 2008

(C) The Author(s) 2008

\begin{abstract}
We here describe four proteins of Chlamydia pneumoniae, which might play a role in host-pathogen interaction. The hypothetical bacterial proteins $\mathrm{CPn} 0708$ and $\mathrm{CPn} 0712$ were detected in Chlamydia pneumoniaeinfected host cells by indirect immunofluorescence tests with polyclonal antisera raised against the respective proteins. While CPn0708 was localized within the inclusion body, CPn0712 was identified in the inclusion membrane and in the surrounding host cell cytosol. CPn0712 colocalizes with actin, indicating its possible interaction with components of the cytoskeleton. Investigations on CPn0809 and CPn1020, two Chlamydia pneumoniae proteins previously described to be secreted into the host cell cytosol, revealed colocalization with calnexin, a marker for the ER. Neither CPn0712, CPn0809 nor CPn1020 were able to inhibit host cell apoptosis. Furthermore, transient expression of CPn0712, CPn0809 and CPn1020 by the host cell itself had no effect on subsequent infection with Chlamydia pneumoniae. However, microarray analysis of CPn0712-expressing host cells revealed six host cell genes which were regulated as in host cells infected with Chlamydia pneumoniae, indicating the principal usefulness of heterologous expression to study the effect of Chlamydia pneumoniae proteins on host cell modulation.
\end{abstract}

Keywords Chlamydia pneumoniae - Type-III-secretion . Effector proteins

N. Müller · F. Sattelmacher $\cdot$ R. Lugert · U. Groß $(\bowtie)$

Institute for Medical Microbiology,

University of Göttingen, Kreuzbergring 57,

37075 Göttingen, Germany

e-mail: ugross@gwdg.de

\section{Introduction}

The obligate intracellular pathogens of the genus Chlamydia share a unique life cycle. The infection is initiated by metabolically dormant elementary bodies (EBs), which intracellularly develop into metabolically active reticulate bodies (RBs). After numerous rounds of replication, the RBs differentiate back to EBs late in the life cycle which, when liberated from the host cell, invade other cells for subsequent rounds of infection [1].

The entire development cycle takes place inside a vacuole, termed an inclusion body, which separates the Chlamydia from the endocytic pathway of the host cell. Despite this demarcation, Chlamydia are able to take up sphingolipids [19], sphingomyelin [20], cholesterol [6] or glycerophospholipids from the host cell [32]. Furthermore, the bacteria export proteins into the inclusion membrane or via the inclusion membrane into the host cell cytosol to modulate host cell functions and to maintain their intracellular life style. One mechanism of protein secretion is the type III secretion system (TTSS), which allows direct transfer of bacterial effector proteins into the cytoplasm of the host cell. Gene sequences with similarity to structural components and chaperones have been detected in the genome of Chlamydia, but in contrast to TTSSs of other bacteria, these genes are not clustered but scattered throughout the genome [31]. In addition, the expression of a functional TTSS in Chlamydiae has been reported [16, 17]. The TTSS of Chlamydia pneumoniae is composed of 13 proteins, among which YscN plays the role of a putative energizer [40], whereas LcrH-2 and SycE seem to serve as chaperones. Interaction of LcrH-2 with LcrE, the putative "lid" of the TTSS, has recently been described [30].

Several proteins that are secreted by Chlamydia pneumoniae are known at present. Using a heterologous system, 
IncA, IncB, IncC and three hypothetical proteins have been shown to be type III secreted in Shigella flexneri [34]. IncA, IncB, Cpn0308 and Cpn1027 have been localized to the inclusion [3, 18, 25, 26], and the Chlamydia pneumoniae proteins Cpn0809, Cpn1020 and Cpn0797 have been shown to be secreted into the host cell cytosol $[11,25]$. Furthermore, translocation of a chlamydial-secreted protease factor [44] and of Cpn0796 into the host cell cytosol by an autoporter mechanism has been reported [37].

So far, the function of only a few secreted proteins of Chlamydia is known. For example, Chlamydia have been shown to inhibit host cell apoptosis [13], and to alter tyrosine phosphorylation of host cell proteins [14]. Furthermore, Chlamydia are able to suppress MHC class I and II expression by degradation of transcription factors RFX5 and USF1 [42, 43]. In Chlamydia trachomatis, IncA has been shown to be important for fusogenicity of inclusions since the absence of IncA leads to a non-fusogenic phenotype [36]. Furthermore, CT456 (Tarp), a type III-secreted protein, has been demonstrated to be associated with the recruitment of actin which mediates the internalization of the pathogen [7].

Nevertheless, finding further proteins that are translocated into the host cell cytosol remains a challenge. In the case of the TTSS, for example, the basal apparatus can be identified by its homology to genes of the corresponding system of other bacteria. In contrast, genes encoding proteins that are secreted are specific for the respective bacterial species and, thus, can hardly be identified on the basis of genomic data. However, Bannantine et al. [4] were able to deduce Inc-like proteins by screening each open reading frame of the Chlamydia trachomatis genome for a characteristic hydrophobic domain, resulting in the identification of 46 candidate Inc proteins. Furthermore, 24 new type IIIsecreted proteins were detected with a secretion assay based on the recognition of TTSS signals in Shigella flexneri [35]. In addition, the genetic organization of type III clusters might lead to the identification of translocated proteins, since genes encoding these proteins are often located closely to their respective chaperones [33].

The corresponding genes of cpn0709 and cpn0713 in the genome of Chlamydia trachomatis are ct667 and ct663. Both genes are hypothetical but $c t 663$ possesses homology to the type III-chaperone (CesT) of enteropathogenic E. coli which is needed for the translocation of of the intimin receptor (Tir) protein and for the delivery of Map [9]. In addition, ct667 contains a tetratricopeptide repeat domain (TPR) shown to be important for the interaction of the Yersinia chaperone LcrH with its respective substrates YopB and YopD [12]. Consequently, and because these genes are localized within a subcluster coding for genes of the type III apparatus, they might serve as chaperones for proteins which are translocated by this system. Therefore, we have chosen the adjacent Chlamydia pneumoniae genes cpn708 and $\operatorname{cpn} 712$, the latter is thought to be an adenylate cyclaselike protein phosphorylated by PknD [22], for the investigation of transcription, localization and putative colocalization with host cell components. In addition, we demonstrate the colocalization of Cpn0809 and CPn1020, two Chlamydia pneumoniae proteins which have previously been shown to be released into the cytosol of the host cell [25]. Finally, we report on the use of a cDNA array to gain insight into the putative function of these effector proteins.

\section{Methods}

\section{Chlamydia propagation}

Chlamydia pneumoniae strain AR39 was propagated in HEp-2 and HeLa cells. Monolayers of cells in six-well plates were infected with Chlamydia pneumoniae and centrifuged at $2,000 \mathrm{~g}$ for $45 \mathrm{~min}$ at $35^{\circ} \mathrm{C}$. Afterwards, the supernatant was replaced by serum-free EMEM medium (Biochrom KG) supplemented with $1 \times$ nonessential amino acids, $1 \%$ glutamine, $25 \mu \mathrm{g} / \mathrm{ml}$ gentamicin, $2.5 \mu \mathrm{g} / \mathrm{ml}$ amphotericin B and with $1 \mu \mathrm{g} / \mathrm{ml}$ cycloheximide. Seventytwo hours p.i. bacterial suspensions were centrifuged at $800 \mathrm{~g}$ and supernatants were either stored at $-70^{\circ} \mathrm{C}$ or directly used to infect HEp-2 or HeLa cells. Multiplicity of infection (MOI) was determined by infection of HEp-2 or HeLa cells with different dilutions of Chlamydia pneumoniae AR39 followed by Giemsa staining $60 \mathrm{~h}$ after infection and counting of inclusion bodies per 100 cells.

Cell culture

HEp- 2 and HeLa cells were cultured in EMEM medium containing $10 \% \mathrm{FCS}$ and $1 \times$ nonessential amino acids, $1 \%$ glutamine, $25 \mu \mathrm{g} / \mathrm{ml}$ gentamicin and $2.5 \mu \mathrm{g} / \mathrm{ml}$ amphotericin B.

RNA extraction and reverse transcriptase-PCR assays

Total RNA from infected HEp-2 cells (MOI 1) was prepared using the RNeasy Mini Kit (Qiagen) following the instructions of the manufacturer. After RNA extraction, samples were treated with RNase-free DNase (Promega). To ensure that the prepared RNA contained no contaminating DNA which would adulterate the results of the RT-PCR assays, PCR assays were performed for the $16 \mathrm{~S}$ gene of Chlamydia. Reverse transcriptase (RT)-PCR assays were carried out with the OneStep RT-PCR Kit (Qiagen) as instructed by the manufacturer. Thereafter $100 \mathrm{ng}$ total RNA was reversed transcribed for $30 \mathrm{~min}$ at $50^{\circ} \mathrm{C}$, HotStar Taq DNA polymerase (Roche) was initially activated for $15 \mathrm{~min}$ at $94^{\circ} \mathrm{C}$. Sixteen cycles $(16 \mathrm{~S})$ or 36 cycles 
(cpn0712, cpn0708) of amplification were then carried out according to the following protocol: cDNA was denatured at $94^{\circ} \mathrm{C}$ for $1 \mathrm{~min}$, primer (Table 1) annealed at $50^{\circ} \mathrm{C}$ (cpn0708) or $40^{\circ} \mathrm{C}$ (cpn0712) for $1 \mathrm{~min}$ and extended at $72^{\circ} \mathrm{C}$ for $1 \mathrm{~min}$, with a final incubation at $72^{\circ} \mathrm{C}$ for $10 \mathrm{~min}$. PCR products were analyzed on a $1.5 \%$ agarose gel containing ethidium bromide at a final concentration of $1 \mu \mathrm{g} /$ ml. All PCR signals were normalized against the signal of the $16 \mathrm{~S}$ gene. For this purpose, $16 \mathrm{~S}$ signals were scanned and the volume of the band images were quantitated (ScanPack 3.0, Biometra).

Cloning and expression of Cpn0708 in E. coli DH5 $\alpha$

The open reading frame of cpn0708 was PCR-amplified with specific primers harboring restriction sites for BamHI and HindIII, respectively (Table 1). A PCR was carried out in a TRIO-Thermocycler (Biometra) with $10 \mathrm{ng}$ of genomic DNA of Chlamydia pneumoniae as a template. $50 \mu \mathrm{l}$ of PCR mixture contained $10 \mathrm{mM}$ Tris- $\mathrm{HCl} \mathrm{pH} 8.3,50 \mathrm{mM}$ $\mathrm{KCl}, 1.5 \mathrm{mM} \mathrm{MgCl}_{2}$, dNTPs (each $0.2 \mathrm{mM}$ ), 50 pmol of each primer and 2.5 U Taq DNA Polymerase (Roche). Initial incubation at $95^{\circ} \mathrm{C}$ for 3 min was followed by 40 cycles at $95^{\circ} \mathrm{C}$ for $30 \mathrm{~s}, 50^{\circ} \mathrm{C}$ for $30 \mathrm{~s}$ and $72^{\circ} \mathrm{C}$ for $1 \mathrm{~min}$, with a final incubation at $72^{\circ} \mathrm{C}$ for $5 \mathrm{~min}$. The PCR product was purified, restricted and cloned into prokaryotic expression vector pQE30 (Qiagen). After transformation of E. coli DH5 $\alpha$, expression and purification was performed according to the QIA expression system (Qiagen).

\section{KLH coupling}

Since expression of Cpn0712 in E. coli failed for unknown reasons, a peptide (DLEPRQTSETNHSPK, Eurogentec)
Table 1 Oligonucleotide primers used for RT-PCR analysis and cloning of Chlamydia pneumoniae genes

\begin{tabular}{|c|c|c|}
\hline Gene & Primer name & Sequence $\left(5^{\prime}\right.$ to $\left.3^{\prime}\right)$ \\
\hline \multicolumn{3}{|c|}{ RT-PCR analysis } \\
\hline \multirow[t]{2}{*}{$16 S$} & $16 \mathrm{~S}$ forward & GGA ATA CTC ATA CGG AGC AA \\
\hline & $16 \mathrm{~S}$ reverse & AGG TAA GAA CTG CTT GCA GG \\
\hline \multirow[t]{2}{*}{ cpn0708 } & 708 forward & TGG TTT TGC TCG TCT GCA GG \\
\hline & 708 reverse & ATC TAT AAC TCA GAA TTC TG \\
\hline \multirow[t]{2}{*}{ cpn712 } & 712 forward & TGA ATC ATT AGA AAA ATT TT \\
\hline & 712 reverse & GGG ATA AGC TGG TCT ATA GG \\
\hline \multicolumn{3}{|c|}{ Cloning in $\mathrm{pQE} 30$} \\
\hline \multirow[t]{2}{*}{ cpn0708 } & $\mathrm{CPn} 0708 \mathrm{~F}$ & NNN NNN GGA TCC ATG ATA GAC CCT GTA GAA \\
\hline & CPn0708R & NNN NNN $\underline{\text { AAG CTT TTA ACC TAA TTG CGT TGT }}$ \\
\hline \multicolumn{3}{|c|}{ Cloning in pcDNA4/TO/myc } \\
\hline \multirow[t]{2}{*}{ cpn0712 } & $712 \mathrm{H} 1 \mathrm{~B}$ & CCA CCA TGG ATG GCA GTA CGA TTA ATT GTT GAT \\
\hline & $712 \mathrm{H} 2 \mathrm{~B}$ & TTT ATT GTA GTC TAT TTT ATA TTC AAC CC* \\
\hline \multirow[t]{2}{*}{ cpn0809 } & $809 \mathrm{H} 1$ & CCA CCA TGG CTA TTT CAT CTT CTT CAG G \\
\hline & $809 \mathrm{H} 2 \mathrm{~B}$ & ATT ATT GGT TTT ATG TGC GCC AGC \\
\hline \multirow[t]{2}{*}{ cpn1020 } & $1020 \mathrm{H} 1$ & CCA CCA TGC CCT CTT GTT TAT CTC AAG C \\
\hline & $1020 \mathrm{H} 2$ & TCC TCT TAA GGA GTG GAG ATA C \\
\hline \multicolumn{3}{|c|}{ Real time RT-PCR (LightCycler) } \\
\hline \multirow[t]{2}{*}{$g 3 p d h$} & forward & TGA AGG TCG GAG TCA ACG CAT TTG GT \\
\hline & reverse & CAT GTG GGC CAT GCG GTC CAC CAC \\
\hline \multirow[t]{2}{*}{ ifit1 } & forward & GAA GCC CTG GAG TAC TAT G \\
\hline & reverse & CAA GAA TTA CAT CAT TAC AGT G \\
\hline \multirow[t]{2}{*}{ ifit3 } & forward & CAG GAG AAT CTG AAG CTA GTG \\
\hline & reverse & GCT TTT CAG CAT CAG GGA C \\
\hline \multirow[t]{2}{*}{ eif5 } & forward & CTT GCC AAA GAG ATT CGT GTC \\
\hline & reverse & CGA TGT CGT CAT CCT TGT TG \\
\hline \multirow[t]{2}{*}{$g l p 2 r$} & forward & CTG GTC CTC ATT CCT TTA TTA TTG \\
\hline & reverse & GCC TTC ACT TCT CCA TTG G \\
\hline \multirow[t]{2}{*}{ ttll11 } & forward & CGC CTG GCA GGG ACC C \\
\hline & reverse & ACA AAA CTT AGA GAG TCC G \\
\hline \multirow[t]{2}{*}{ loc464157 } & forward & GTA TAT TCA GAA GAA CAC AGA T \\
\hline & reverse & CTA GAA ATG GGA CTC TCA G \\
\hline
\end{tabular}

Restriction sites for cloning in pQE30 are underlined, Kozak sequences for eukaryotic expression are in bold 
representing the amino acids 133-147 of CPn0712 was coupled to keyhole limpet hemocyanin (KLH) to obtain an antigen suitable for immunization. Ten milligrams of KLH was dissolved in $\mathrm{ddH}_{2} \mathrm{O}$ and incubated with ethyl maleimide solution in PBS for 30 min at RT to block free SHgroups. After dialysis against $50 \mathrm{mM}$ phosphate buffer $\mathrm{pH}$ $7.5, \mathrm{KLH}$ was incubated with $1.25 \mathrm{mg}$ of SMCC-sulfo in a total volume of $1.5 \mathrm{ml}$. The KLH solution was passed through a PD10 column and eluted in $1.5 \mathrm{ml}$ phosphate buffer, $\mathrm{pH}$ 6.8. Five milligrams of the peptide (amino acids 133-147 of CPn0712) were dissolved in $1 \mathrm{ml}$ of the same buffer and coupled to KLH by adding the peptide solution dropwise to the KLH eluate. Finally, the conjugate was incubated with shaking for $2 \mathrm{~h}$ and dialyzed against PBS.

\section{Immunization}

New Zealand white rabbits were injected subcutanously with $100 \mu \mathrm{g}$ of recombinant Cpn0708 or $100 \mu \mathrm{g}$ KLH-coupled Cpn0712 peptide suspended in ABM-S (Linaris), respectively. On days 14 and 28, rabbits were boosted with the same amounts of antigen suspended in ABM-N (Linaris). Rabbits were bled on day 42 and the sera were stored at $-20^{\circ} \mathrm{C}$.

Immunofluorescence microscopy for the detection of $\mathrm{CPn} 0712$ and $\mathrm{CPn} 0708$

Chlamydia pneumoniae-infected HEp-2 cells grown on coverslips were fixed with $4 \%$ paraformaldehyde in PBS for $10 \mathrm{~min}$ at room temperature, followed by permeabilization with $1 \%$ NP40 in PBS for 10 min. Samples were blocked with $1 \%$ BSA and after having been washed, cells were subjected to antibody staining. Poyclonal rabbit antisera $(\alpha \mathrm{CPn} 0708$ and $\alpha \mathrm{CPn} 0712)$ were added at a dilution of 1:100 in 1\% BSA in PBS for an overnight incubation. For double immunostaining, samples were additionally incubated with a murine primary antibody directed against Chlamydia pneumoniae (Acris) at a 1:200 dilution. For visualization, Cy2-conjugated secondary anti-rabbit antibody in combination with a Cy3-conjugated secondary anti-mouse antibody, each at a dilution of 1:500, were used. Finally, the samples were analyzed using a conventional immunofluorescence microscope (Leica, DMIL).

Cloning of cpn0712, cpn0809 and cpn1020

in an eukaryotic expression vector

The coding region of cpn0712, cpn0809 and cpn1020 was PCR-amplified using primers indicated in Table 1. A Kozak sequence was introduced into each amplification product to be cloned. A PCR was carried out using a TRIOThermocycler (Biometra) with genomic DNA of Chla- mydia pneumoniae AR39 as a template. Initial incubation at $95^{\circ} \mathrm{C}$ for $3 \mathrm{~min}$ was followed by 40 cycles at $95^{\circ} \mathrm{C}$ for $30 \mathrm{~s}, 59^{\circ} \mathrm{C}$ for $30 \mathrm{~s}$, and $72^{\circ} \mathrm{C}$ for $2 \mathrm{~min}$, with a final incubation at $72^{\circ} \mathrm{C}$ for $5 \mathrm{~min}$. PCR products were purified (QIAquick PCR Purification Kit, Qiagen) and cloned into eukaryotic expression vector pcDNA4/TO/myc-His (Invitrogen) according to the instructions of the manufacturer.

Transfection of HeLa cells and subsequent immunodetection of expressed proteins

HeLa cells grown on sterile glass coverslips were transfected with the generated eukaryotic expression vectors using jet PEI (Polyplus) following the manual of the manufacturer. Fixation and permeabilization were carried out as described above. In some experiments, transfected cells were treated with 10 or $100 \mu \mathrm{g} / \mathrm{ml}$ colchicine for $4 \mathrm{~h}$ before fixation. A murine monoclonal antibody against the myctag, a goat monoclonal antibody against calnexin and a polyclonal antiserum against actin (Santa Cruz Biotechnology) were used at a dilution of 1:200, respectively. A polyclonal antiserum against IncA raised in a New Zealand White rabbit was diluted 1:50 and the reaction was subsequently visualized with an appropiate DTAF-conjugated secondary antibody at a dilution of 1:1,000. Recombinant proteins cloned in fusion with a myc-tag were visualized with the monoclonal mouse antibody against myc in combination with a Cy2-conjugated secondary antibody (1:500), whereas detection of calnexin and $\alpha$-actin was carried out with a Cy3-conjugated secondary antibody at a dilution of 1:500. The immunofluorescence images were obtained using a Leica SP2 confocal immunofluorescence microscope.

\section{Apoptosis assays}

HeLa cells were transfected with pcDNA4/TO/myc carrying either cpn0712, cpn0809 or cpn1020. Twenty-four hours later, cells were incubated with $1 \mu \mathrm{M}$ staurosporine and incubated for $3.5 \mathrm{~h}$. Cells were fixed and immunofluorescence assays were carried out as described above. After incubation with the secondary antibody, Hoechst 33258 $(50 \mathrm{ng} / \mathrm{ml})$ in PBS was added for $1 \mathrm{~h}$ to stain the nuclei of the cells. All assays were analyzed using a conventional immunofluorescence microscope (Leica, DMIL).

\section{Microarrays}

RNA was prepared from cpn0712-transfected HeLa cells and HeLa cells transfected with an empty vector using the Qiagen RNeasy Kit according to the manufacturer's recommendations and stored at $-80^{\circ} \mathrm{C}$. Afterwards, the samples were DNAse I treated in order to remove genomic DNA 
contamination. RNA quality was determined using the Agilent 2100 Bioanalyzer (Agilent Technologies) microfluidic electrophoresis. For gene expression profiling, a two-color $1 \times 2$ design including a dye swap using four arrays was applied. The labeled DNA samples for microarray hybridization were prepared from $0.8 \mu \mathrm{g}$ of total RNA according to the Atlas SMART Fluorescent Probe Amplification Kit (Clontech-Takara Bio Europe) protocol, except that (1) the RNA template was hydrolyzed under alkaline conditions before cDNA purification, and (2) the PCR amplification process was monitored and stopped in the exponential phase. Quantity and dye incorporation rates of the converted RNA were assessed using a NanoDrop ND-100. Per microarray, $2 \mu \mathrm{g}$ of Cy3- and Cy5-labeled cDNA fragments, respectively, were hybridized to Agilent Technologies 44K Human Whole Genome Microarrays (G4112A) for $17 \mathrm{~h}$ at $65^{\circ} \mathrm{C}$. Post processing, washes were carried out according to the Agilent Technologies SSPE protocol (v2.1), wash solution 3 being replaced by acetonitril, followed by immediate scanning using an Agilent G2505B scanner. Intensity data were extracted using the software 'Automatic Imageprocessing for Microarrays'. Normalization of the raw intensity data was achieved with a non-linear loess regression. Differentially expressed genes were identified by an ANOVA fixed effects model. $P$-values were obtained from component-wise $t$-tests, adjusted with the Benjamini-Hochberg method to control the False-Discovery-Rate. Normalization and statistical computation was carried out for two independent datasets derived from a high gain and a low gain scan, allowing replacement of saturated features in the high gain scan with data from the low gain measurement.

In order to compare the gene regulation pattern of CPn0712 expressing HeLa cells with cells that had been infected by Chlamydia pneumoniae, RNA of infected and non-infected cells was prepared with the Qiagen RNeasy kit. Subsequently, host cell genes that were regulated in CPn0712 expressing cells were tested in a second microarray following the schedule mentioned above.

\section{Real time RT-PCR}

To confirm the results of the microarrays, semiquantitative real time RT-PCRs with the LightCycler 1.5 (Roche) were carried out. Remaining RNA samples from the microarrays were used as templates. Total RNA was reverse transcribed with oligo-dT primers according to the Omniscript RT Kit (Qiagen). Subsequently, $100 \mathrm{ng}$ of cDNA was used for each of the following PCR assays, respectively. The amount of primers in every PCR assay performed was 10 pmol. Primer sequences are listed in Table 1. PCR runs were carried out with the LightCycler FastStart DNA Master Set using SYBR Green I for the detection of amplicons. PCR conditions were as follows: after initial denaturation for $10 \mathrm{~min}$ at $95^{\circ} \mathrm{C}$, amplification was performed with 40 cycles of denaturation $\left(10 \mathrm{~s} ; 95^{\circ} \mathrm{C}\right)$, annealing $\left(10 \mathrm{~s} ; 55^{\circ} \mathrm{C}\right)$ and elongation $\left(10 \mathrm{~s} ; 72^{\circ} \mathrm{C}\right)$. Amplicons of $g 3 p d h$, a gene that is expressed constitutively, were used to adjust the following PCRs based on the crossing points obtained for this gene.

\section{Results and discussion}

Transcription of cpn0708 and cpn0712

RT-PCR assays of Chlamydia pneumoniae RNA were carried out to examine the transcription of cpn0708 and cpn0712. HEp-2 cells were infected with Chlamydia pneumoniae and RT-PCR assays were performed at 2, 8, 24, 48 and $72 \mathrm{~h}$ p.i. Signals for the 16S-RNA gene were used as an internal standard. Using $100 \mathrm{ng}$ total RNA of Chlamydia pneumoniae-infected HEp-2 cells, we were able to detect transcription of cpn0708 at $2 \mathrm{~h}$ and cpn0712 at $8 \mathrm{~h}$ p.i. (Fig. 1). The primers used in this assay are listed in Table 1.

\section{Expression and localization of CPn0708 and CPn0712}

The gene encoding cpn0708 was cloned in the prokaryotic expression vector pQE30, expressed in E. coli and purified. In contrast and for unknown reasons, $\mathrm{CPn} 0712$ failed to be expressed in E. coli. Instead and to generate an antiserum also against $\mathrm{CPn} 0712$, a peptide corresponding to the amino acids 133-147 was coupled to KLH. Recombinant CPn0708 and the KLH-conjugate were then used to generate antisera in rabbits.

To determine the expression and intracellular localization of Cpn0708 and Cpn0712, double immunofluorescence assays with antisera against the respective proteins and a monoclonal antibody against Chlamydia pneumoniae were

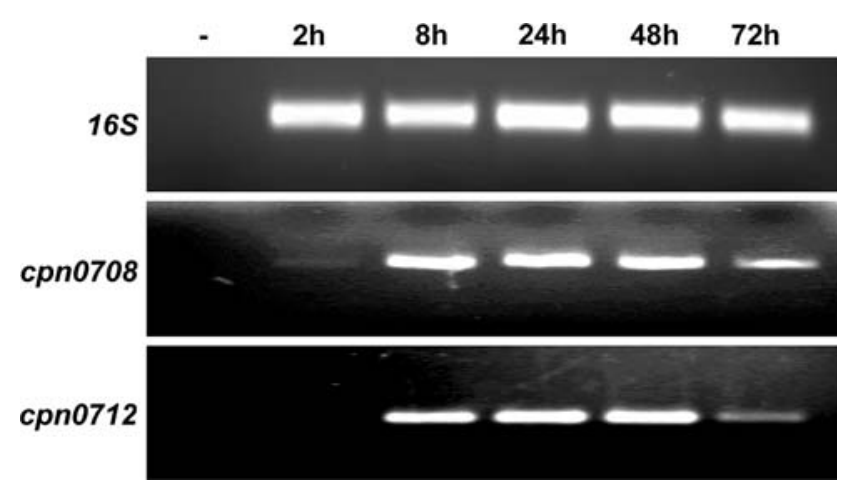

Fig. 1 RT-PCR analysis of cpn0708 and cpn0712. Primer pairs and length of the amplicons are listed in Table 1. RNA from non-infected cells was used as negative control (-). RNA as a template for PCR without previous RT reaction yielded no bands (not shown) 
carried out. HEp-2 cells were infected with Chlamydia pneumoniae (MOI 2.3) and fixed $60 \mathrm{~h}$ after infection. Whereas immunofluorescence tests with the antiserum against Cpn0708 gave a clear and homologous staining only within the inclusion bodies (Fig. 2a), signals for Cpn0712 were nonuniform. We obtained an antibody reaction with the inclusion membrane confirming the results by Herrmann et al. [21] and also with the surrounding cytosol of the infected cell, giving rise to the idea, that in certain amounts, Cpn0712 is also present in the cystosol of the infected cell (Fig. 2b).

Colocalization of Cpn0712, Cpn0809 and Cpn1020 with host cell components

Next, we tried to determine whether a possible colocalization of bacterial effector proteins with host cell components might exist. For this purpose, in addition to CPn0712, we also expressed CPn0809 and CPn1020, two proteins we had previously described, in fusion with a myc-tag in HeLa cells and performed double immunofluorescence assays with a monoclonal antibody against myc and a polyclonal antiserum raised against actin in order to identify a possible colocalization with components of the host cell cytoskeleton. Furthermore, we used a monoclonal antibody against calnexin as a marker for a possible colocalization with the endoplasmatic reticulum. Thereby, Cpn0712 could be colocalized with actin (Fig. 3a). Even after treatment of the Cpn0712-transfected cells with colchicine, an alkaloid that strongly inhibits microtubule polymerization, colocalization of CPn0712 and actin could be demonstrated. Therefore, we have indications that $\mathrm{CPn} 0712$ interacts with components of the host cell cytoskeleton (Fig. 3b).
Furthermore, the antibody reactions for $\mathrm{CPn} 0809$ and CPn1020 matched those of calnexin, indicating a colocalization with the endoplasmatic reticulum (Fig. 3c, d). Since neither a colocalization of $\mathrm{CPn} 0712$ with calnexin, nor colocalizations of CPn0809 and CPn1020 with actin could be detected (data not shown), we judge the above-mentioned colocalization to be specific.

Chlamydia pneumoniae infection of host cells is not affected by heterologous expression of CPn0712, CPn0809 or CPn 1020

Alzhanov et al. [2] demonstrated that expression of Chlamydophila caviae IncA within the host cell reduced inclusion formation after subsequent infection with the pathogen. In addition, within the few cells that were infected the inclusions of Chlamydophila caviae were aberrant suggesting that the reduction in titer is a result of interference of IncA with the development of Chlamydophila caviae. To test, whether heterologous expression of CPn0712, CPn0809 and CPn1020 by the host cell could also affect infection and development of Chlamydia pneumoniae we transiently transfected HeLa cells with the corresponding bacterial genes. Twentyfour hours after transfection, the cells were infected with Chlamydia pneumoniae. A further 24 and $48 \mathrm{~h}$ later, we compared the number of infected cells that were infected subsequently with Chlamydia pneumoniae with the number of infected cells not transfected before by counting 100 cells of each coverslip by random views. We found that HeLa cells are equally susceptible to Chlamydia pneumoniae whether or not CPn0712, CPn0809 or CPn1020 are expressed before infection. For example,
Fig. 2 Localization of $\mathrm{CPn} 0708$ and CPn0712 in infected HEp-2 cells. The intracellular localization of $\mathrm{CPn} 0708$ and $\mathrm{CPn} 0712$ was determined with rabbit antisera raised against the respective antigens and visualized with a Cy2-conjugated goat anti-rabbit antibody (green fluorescence). Inclusion bodies were stained with a monoclonal antibody against Chlamydia pneumoniae in combination with a Cy3-conjugated secondary antibody (red fluorescence). a Localization of CPn0708 within the inclusion body only. $\mathbf{b}$ Localization of CPn0712 within the inclusion membrane and the sourrounding cytosol of the infected cell
A

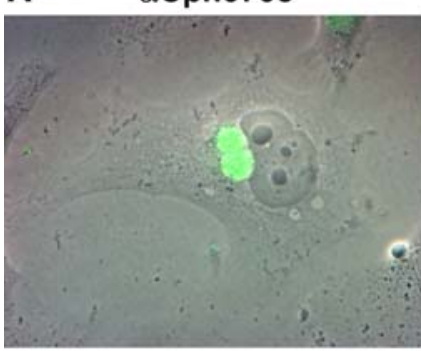

B



$\alpha$ Cpn
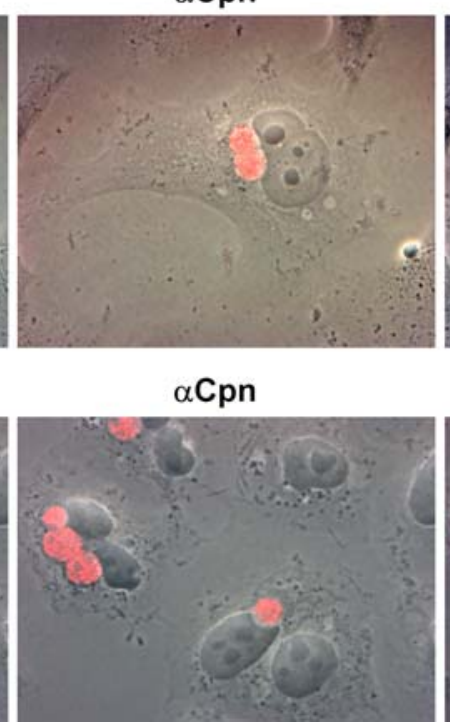
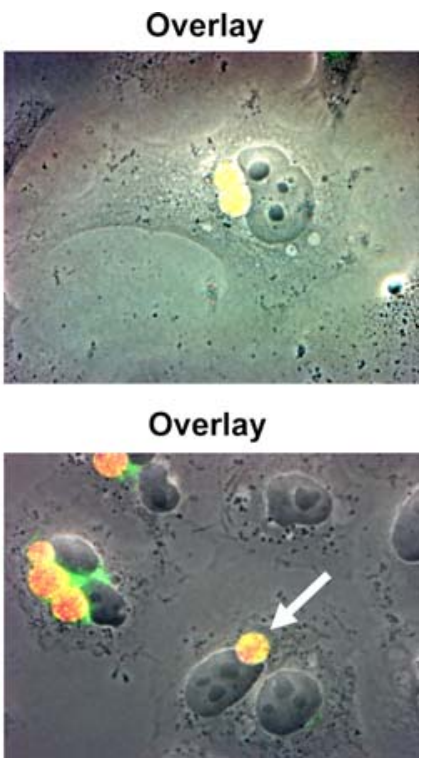
Fig. 3 Colocalization of CPn0712, CPn0809 and CPn1020 with cellular components. The localization of Cpn0712, Cpn0809 and Cpn1020 was detected with a monoclonal antibody against the myc-tag in combination with a Cy2-conjugated secondary antibody (green fluorescence). Actin and calnexin were stained with a polyclonal antiserum and a monoclonal antibody, respectively, and visualized with a Cy3-conjugated secondary antibody (red fluorescence). a Colocalization of CPn0712 with actin. b Identical staining pattern for $\mathrm{CPn} 0712$ and actin after incubation of the transfected cells with colchicine. c, d Colocalization of CPn0809 and CPn1020 with calnexin
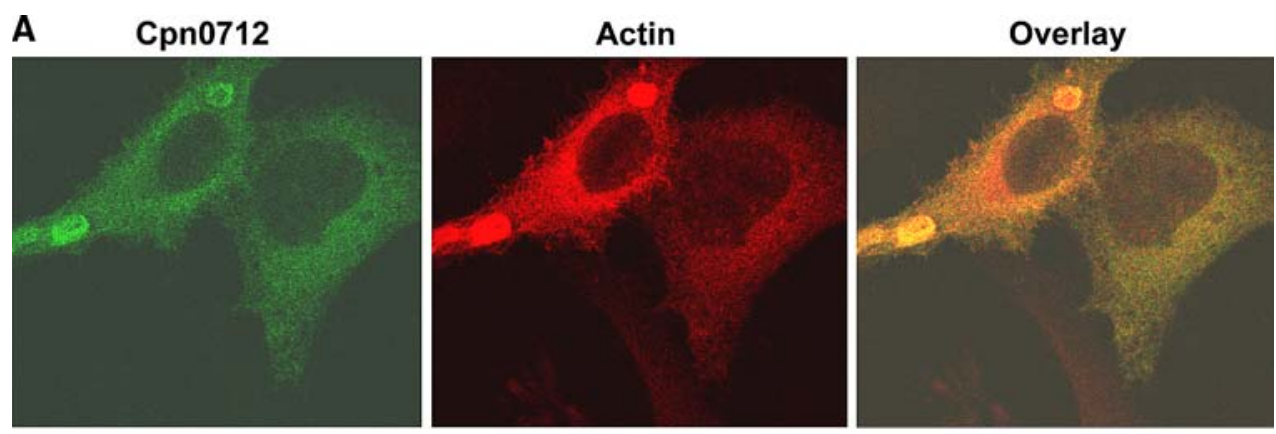

\section{B}

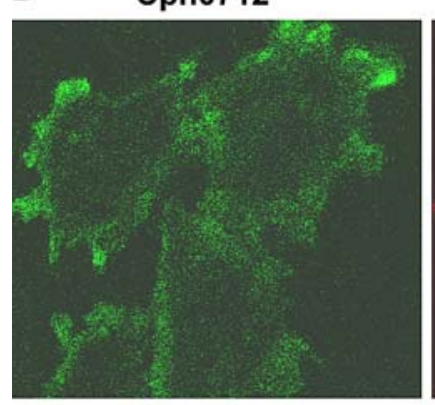

C

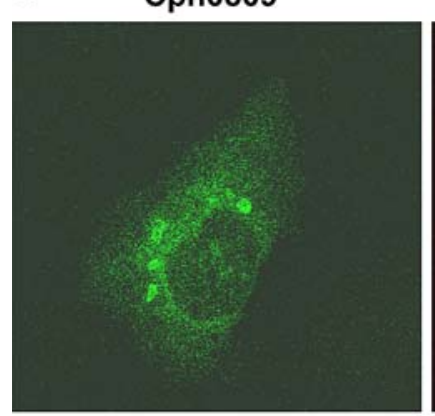

D

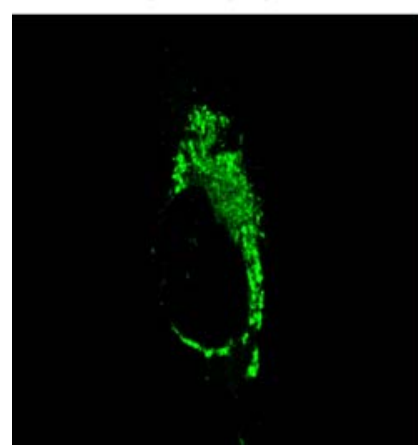

Actin

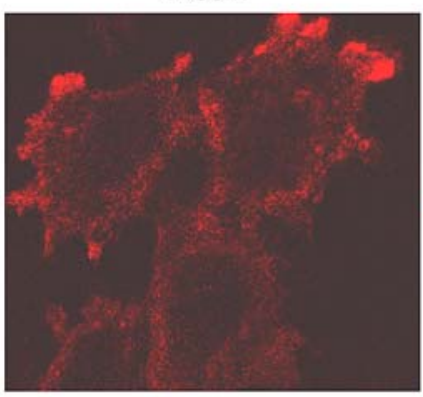

Calnexin



Calnexin

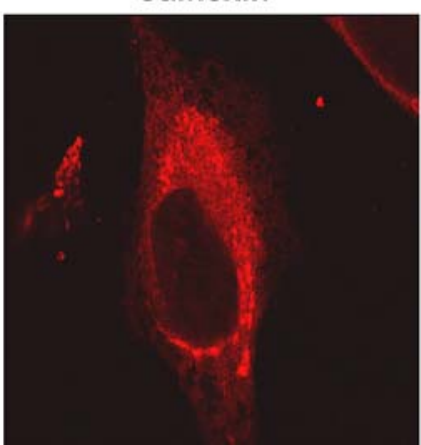

Overlay



Overlay



Overlay

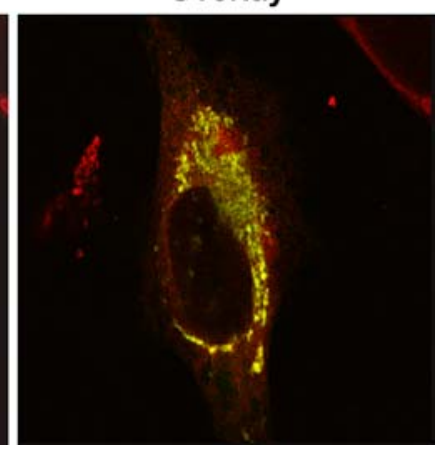

when 100 cells were counted, cells expressing CPn0712 displayed an infection rate of $55 \%$ while $53 \%$ of adjacent but untransfected cells were infected with Chlamydia pneumoniae. Similar results were obtained when cells expressed CPn0809. The infection rate of transfected cells was $47 \%$ compared to $61 \%$ of untransfected cells. In a further experiment, we counted $86 \%$ of CPn1020expressing cells as infected while the infection rate of untransfected cells was $82 \%$.

In addition, we compared the size of the inclusions between transfected and untransfected HeLa cells. An example is shown in Fig. 4. HeLa cells were transiently transfected with the plasmid encoding cpn0809 as mentioned above. Twenty-four hours after transfection, cells were infected with Chlamydia pneumoniae and fixed $48 \mathrm{~h}$ later. Thereby, no differences in the average size of the inclusions could be detected despite expression of the recombinant Chlamydia pneumoniae proteins. 


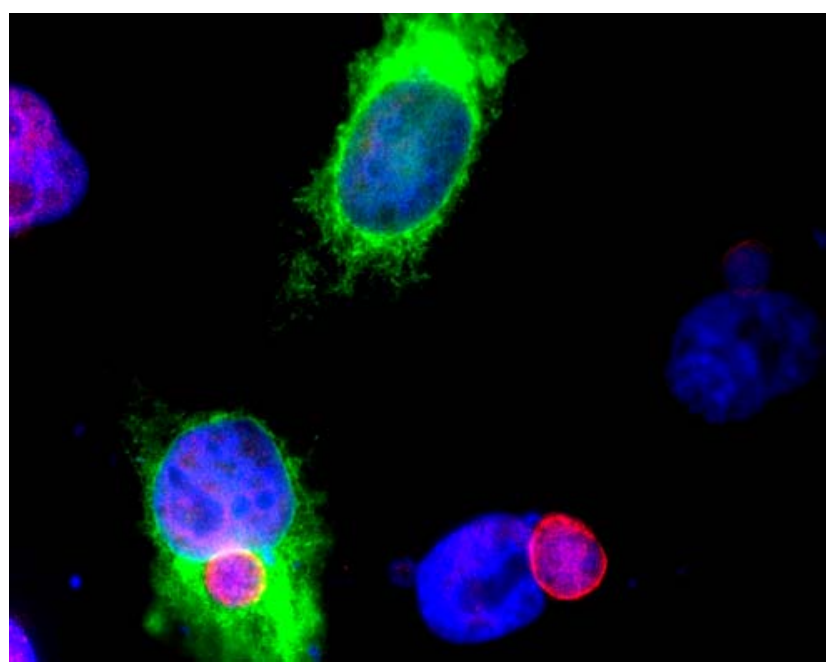

Fig. 4 Heterologous expression of CPn0809 by HeLa cells does not affect the size of the inclusion body when compared with untransfected HeLa cells. CPn0809 was labelled with a monoclonal $\alpha$-myc antibody in combination with a Cy2-conjugated $\alpha$-mouse secondary antibody (green fluorescence). Inclusions were probed with rabbit antisera raised against IncA and visualized with DTAF-conjugated secondary antibody (red fluorescence). Nuclei were stained with Hoechst 33258

Apoptosis is not inhibited by $\mathrm{CPn} 0712, \mathrm{CPn} 0809$ or CPn1020

Inhibition of apoptosis by Chlamydia is a well described and time-dependent process of host cell modulation [28]. Thereby, the pro-apoptotic BH3-only proteins Puma, Bad, Bmf, Noxa and tBid are widely degraded by these intracellular bacteria $[10,15,41]$. To investigate whether CPn0712, CPn0809 or CPn1020 possess anti-apoptotic activity, we transfected HeLa cells with the respective genes. Twenty-four hours later, we incubated the cells for a further $3.5 \mathrm{~h}$ with the non-selective protein kinase inhibitor staurosporine to induce apoptosis, which subsequently was confirmed by the condensation of chromatin using Hoechst staining. HeLa cells that were not treated by staurosporine served as a negative control. Induction of apoptosis was shown in more than $95 \%$ of the cells treated with staurosporine. Since the apoptotic staining pattern caused by staurosporine was identical in cells expressing CPn0712, CPn0809 or CPn1020 compared to untransfected cells, inhibition of apoptosis by these bacterial proteins is unlikely.

Comparison of altered transcription of CPn0712-expressing HeLa cells with Chlamydia pneumoniae-infected host cells

In recent years, cDNA arrays have become a popular method to determine host pathogen interactions. Thus, several microarrays have been carried out to investigate interactions of Chlamydia pneumoniae with different host cells $[8,27,38]$.

In order to determine a possible host cell modulation by Chlamydia pneumoniae proteins, we transiently transfected HeLa cells with cpn0712 as mentioned above. The efficacy of transfection was $40 \%$. The cDNA array revealed a more than threefold downregulation of transcription of 180 genes (75\%) compared to 57 genes $(25 \%)$ whose transcriptions were upregulated with the same magnitude. If the cutoff was adopted at a magnitude of two, 676 genes $(63 \%)$ were downregulated and 400 genes (37\%) were upregulated. The most highly upregulated gene was $c a 9(+5.5)$, encoding for carbonic anhydrase 9 protein, while the most highly downregulated gene was phactr (-7.9), representing the phosphatase and actin regulator four isoform. The altered transcription of certain genes was confirmed by real time RT-PCR assays with the same RNA sample used in the assay. To exclude the possibility that different transcription levels are due to different amounts of RNA, samples were adjusted to the transcription level of the constitutively expressed $g 3 p d h$ gene (not shown).

In order to confirm that heterologous expression of bacterial proteins by HeLa cells is a suitable model to mimic the effect of natural infection, we investigated whether the alteration of gene transcription was similar between CPn0712-expressing and naturally infected HeLa cells, respectively. Fifty-five hours p.i., the RNA of infected and uninfected cells was isolated and applied for a second microarray using all genes that were previously shown to be differently transcribed by $\mathrm{CPn} 0712$ with a magnitude of 2 . Thereby, only 86 of the 1,076 genes tested were regulated with a magnitude of 3 . In addition, from the 86 genes with altered transcription after infection, only 6 were transcribed in a similar way to that following heterologous expression of CPn0712. Real time PCR (LightCycler, Roche) confirmed upregulation and downregulation of transcription of these genes both after infection of HeLa cells with Chlamydia pneumoniae and after transfection with pcDNA4/TO/myc carrying cpn0712 (Table 2). Less is known about the biological function of some of the genes demonstrated to be regulated in the same way by Chlamydia pneumoniae or by $\mathrm{CPn} 0712$ alone. The genes ifit1 and ifit3, both upregulated in our assays, code for interferon-induced proteins with TPRs and are closely located on chromosome 10. Although the function of these genes in vivo is not known, ifit1, ifit 2 and ifit 4 have also been demonstrated to be upregulated after infection of HeLa 229 cells with Chlamydia trachomatis [24]. Furthermore, they have been shown to respond to distinct viral infections in a mouse model [39]. The transcription of the glucagon-like peptide-2 receptor $(g l p 2 r)$ was downregulated by CPn0712. The corresponding protein belongs to the so-called "glucagon-like peptide and secretin" family of seven transmem- 
Table 2 Confirmation of the transcription of genes which were either up- or downregulated after (1) infection of HeLa cells with Chlamydia pneumoniae, or (2) transfection with cpn0712

\begin{tabular}{llllll}
\hline \multirow{2}{*}{ Gene } & \multicolumn{2}{l}{$\begin{array}{l}\text { HeLa cells infected } \\
\text { with Chlamydia pneumoniae }\end{array}$} & & & \multicolumn{2}{l}{$\begin{array}{l}\text { HeLa cells transfected } \\
\text { with cpn0712 }\end{array}$} \\
\cline { 2 - 3 } \cline { 5 - 6 } & RT-PCR & Microarray & & RT-PCR & Microarray \\
\hline ttll11 & -1.22 & -1.60 & & -3.10 & -2.31 \\
eif5 & -3.11 & -2.47 & & -4.17 & -2.19 \\
glp2r & -3.92 & -2.42 & & -2.10 & -2.93 \\
ifit1 & +1.41 & +2.19 & & +2.10 & +2.90 \\
ifit3 & +2.65 & +2.86 & & +1.73 & +2.56 \\
loc491355 & +3.24 & +1.56 & & +3.20 & +2.46 \\
\hline
\end{tabular}

brane receptors and interacts with the glucagon-like peptide, mainly expressed in enteroendocrine epithelial Lcells [5]. Also downregulated was the transcription of ttll11, an enzyme of the large family of tubulin tyrosine ligase-like proteins, whose members catalyze the ligation of amino acids to, for example, tubulin [23].

In contrast to the poorly described genes above, eif5 (eukaryotic initiation factor 5) which was also downregulated in our assay, belongs to the proteins which mediate initiation of translation in a complex process. Thereby, EIF5 was shown to be a component of a multifactor complex comprising other initiation factors, GTP and MettRNA $_{i}$, where EIF5 induces GTPase activity of a further initiation factor, EIF2, if associated with the $40 \mathrm{~S}$ ribosomal subunit [29]. However, none of these genes have been linked to Chlamydia pneumoniae infections, before. Although these genes are regulated in the same direction irrespective of whether cells are infected with Chlamydia pneumoniae or express CPn0712 alone, the biological significance of these effects remains uncertain and awaits further investigations.

Acknowledgments This study was supported by the Deutsche Forschungsgemeinschaft (GR 906/8-2).

Open Access This article is distributed under the terms of the Creative Commons Attribution Noncommercial License which permits any noncommercial use, distribution, and reproduction in any medium, provided the original author(s) and source are credited.

\section{References}

1. Abdelrahman YM, Belland RJ (2005) The chlamydial development cycle. FEMS Microbiol Rev 29:949-959

2. Alzhanov D, Barnes J, Hruby DE, Rockey DD (2004) Chlamydial development is blocked in host cells transfected with Chlamydia caviae incA. BMC Microbiol 4:24

3. Bailey L, Gylfe A, Sundin C, Muschiol S, Elofsson M, Nordstrom P, Henriques-Normark B, Lugert R, Waldenstrom A, Wolf-Watz H (2007) Small molecule inhibitors of type III secretion in Yersinia block the Chlamydia infection cycle. FEBS Lett 581:587-595

4. Bannantine JP, Griffiths RS, Viratyosin W, Brown WJ, Rockey DD (2000) A secondary structure motif predictive of protein local- ization to the chlamydial inclusion membrane. Cell Microbiol $1: 35-47$

5. Buhl T, Thim L, Kofod H, Orskov C, Harling H, Holst JJ (1988) Naturally occuring products of proglucagon 111-160 in the porcine and human small intestine. J Biol Chem 263:8621-8624

6. Carabeo RA, Mead DJ, Hackstadt T (2003) Golgi-dependent transport of cholesterol to the Chlamydia trachomatis inclusion. Proc Natl Acad Sci USA 100:6771-6776

7. Clifton DR, Fields KA, Grieshaber SS, Dooley CA, Fischer ER, Mead DJ, Carabeo RA, Hackstadt T (2004) A chlamydia type III translocated protein is tyrosine-phosphorylated at the site of entry and associated with recruitment of actin. Proc Natl Acad Sci USA 101:10166-10171

8. Coombes BK, Mahony JB (2001) cDNA array analysis of altered gene expression in human endothelial cells in response to Chlamydia pneumoniae infection. Infect Immun 69:1420-1427

9. Creasey EA, Delahay RM, Bishop AA, Shaw RK, Kenny B, Knutton S, Frankel G (2003) CesT is a bivalent enteropathogenic Escherichia coli chaperone required for translocation of both Tir and Map. Mol Microbiol 47:209-221

10. Dong F, Pirbhai M, Xiao Y, Zhong Y, Wu Y, Zhong G (2005) Degradation of the proapoptotic proteins Bik, Puma, and Bim with Bcl-2 domain 3 homology in Chlamydia trachomatis-infected cells. Infect Immun 73:1861-1864

11. Dong F, Flores R, Chen D, Luo J, Zhong Y, Wu Z, Zhong G (2006) Localization of the hypothetical protein Cpn0797 in the cytoplasm of Chlamydia pneumoniae-infected host cells. Infect Immun 74:6479-6486

12. Edqvist PJ, Broms JE, Betts HJ, Forsberg A, Pallen MJ, Francis MS (2006) Tetratricopeptide repeats in the type III secretion chaperone, LcrH: their role in substrate binding and secretion. Mol Microbiol 59:31-44

13. Fan T, Lu H, Hu H, Shi L, McClarty GA, Nance DM (1998) Inhibition of apoptosis in Chlamydia-infected cells: blockade of mitochondrial cytochrome $\mathrm{c}$ release and caspase activation. J Exp Med 187:487-496

14. Fawaz FS, van Ooij C, Homola E, Mutka SC, Engel JN (1997) Infection with Chlamydia trachomatis alters the tyrosine phosphorylation and/or localisation of several host cell proteins including cortactin. Infect Immun 65:5301-5308

15. Fischer SF, Vier J, Kirschnek S, Klos A, Hess S, Ying S, Hacker $\mathrm{G}$ (2004) Chlamydia inhibit host cell apoptosis by degradation of proapoptotic BH3-only proteins. J Exp Med 200:905-916

16. Fields KA, Hackstadt T (2000) Evidence for secretion of Chlamydia trachomatis CopN by a type III secretion mechanism. Mol Microbiol 38:1048-1060

17. Fields KA, Mead DJ, Dooley CA, Hackstadt T (2003) Chlamydia trachomatis type III secretion: evidence for a functional apparatus during early-cycle development. Mol Microbiol 48:671-683

18. Flores R, Luo J, Chen D, Sturgeon G, Shivshankar P, Zhong Y, Zhong G (2007) Characterization of the hypothetical protein 
Cpn1027, a newly identified inclusion membrane protein unique to Chlamydia pneumoniae. Microbiology 153:777-786

19. Hackstadt T, Scidmore MA, Rockey DD (1995) Lipid metabolism in Chlamydia trachomatis-infected cells: direct trafficing of Golgiderived sphingolipids to the chlamydial inclusion. Proc Natl Acad Sci USA 92:4877-4881

20. Hackstadt T, Rockey DD, Heinzen RA, Scidmore MA (1996) Chlamydia trachomatis interrupts an exocytic pathway to acquire endogenously synthesized sphingomyelin in transit from the Golgi apparatus to the plasma membrane. EMBO J 15:964-977

21. Herrmann M, Schuhmacher A, Mühldorfer I, Melchers K, Prothmann C, Dammeier S (2006) Identification and characterization of secreted effector proteins of Chlamydophila pneumoniae TW183. Res Microbiol 157:513-524

22. Johnson DL, Mahony JB (2007) Chlamydophila pneumoniae PknD exhibits dual amino acid specifity and phosphorylates Cpn0712, a putative type III secretion YscD homolog. J Bacteriol 189:7549-7555

23. Janke C, Rogowski K, Wloga D, Regnard C, Kajava AV, Strub JM, Temurak N, van Dijk J, Boucher D, van Dorsselaer A, Suryavanshi S, Gaertig J, Edde B (2005) Tubulin polyglutamylase enzymes are members of the TTL domain protein family. Science 308:1758-1762

24. Lad SP, Fukuda EY, Li J, de la Masa LM, Li E (2005) Up-regulation of JAK/STAT1 signal pathway during Chlamydia trachomatis infection. J Immunol 174:7186-7193

25. Lugert R, Kuhns M, Polch T, Gross U (2004) Expression and localization of type III secretion-related proteins of Chlamydia pneumoniae. Med Microbiol Immunol 193:163-171

26. Luo J, Jia T, Flores R, Chen D, Zhong G (2007) Hypothetical protein Cpn0308 is localized in the Chlamydia pneumoniae inclusion membrane. Infect Immun 75:497-503

27. Mannonen L, Nikula T, Haveri A, Reinikainen A, Vuola JM, Lahesmaa R, Puolakkainen M (2007) Up-regulation of host cell genes during interferon-gamma-induced persistent Chlamydia pneumoniae infection in HL cells. J Infect Dis 195:212-219

28. Miyairi I, Byrne GI (2006) Chlamydia and programmed cell death. Curr Opin Microbiol 9:102-108

29. Pestova TV, Kolupaeva VG, Lomakin IB, Pilipenko EV, Shatsk IN, Agol VI, Hellen CU (2001) Molecular mechanisms of translation initiation in eukaryotes. Proc Natl Acad Sci USA 98:7029-7036

30. Slepenkin A, de la Maza LM, Peterson EM (2005) Interaction between components of the type III secretion system of Chlamydiaceae. J Bacteriol 187:473-479

31. Stephens RS, Kalman S, Lammel C, Fan J, Marathe R, Aravind L, Mitchell W, Olinger L, Tatusov RL, Zhao Q, Koonin EV, Davis RW (1998) Genome sequence of an obligate intracellular pathogen of humans: Chlamydia trachomatis. Science 23:754-759

32. Su H, McClarty G, Dong F, Hatch GM, Pan ZK, Zhong G (2004) Activation of Raf/MEK/ERK/cPLA2 signaling pathway is essen- tial for chlamydial acquisition of host glycerophospholipids. J Biol Chem 279:9409-9416

33. Subtil A, Blocker A, Dautry-Varsat A (2000) Type III secretion system in Chlamydia species: identified members and candidates. Microbes Infect 2:367-369

34. Subtil A, Parsot C, Dautry-Varsat A (2001) Secretion of predicted Inc proteins of Chlamydia. pneumoniae by a heterologous type III machinery. Mol Microbiol 39:792-800

35. Subtil A, Delevoye C, Balana ME, Tastevin L, Perrinet S, DautryVarsat A (2005) A direct screen for chlamydial proteins secreted by a type III mechanism identifies a translocated protein and numerous other candidates. Mol Microbiol 56:1636-1647

36. Suchland RJ, Rockey DD, Bannantine JP, Stamm WE (2000) Isolates of Chlamydia trachomatis that occupy nonfusogenic inclusions lack IncA, a protein localized to the inclusion membrane. Infect Immun 68:360-367

37. Vandahl BB, Stensballe A, Roepstorff P, Christiansen G, Birkelund S (2005) Secretion of Cpn0796 from Chlamydia pneumoniae into the host cell cytoplasm by an autotransporter mechanism. Cell Microbiol 7:825-836

38. Virok D, Loboda A, Kari L, Nebozhyn M, Chang C, Nichols C, Endresz V, Gonczol E, Berensci K, Showe MK, Showe LC (2003) Infection of U937 monocytic cells with Chlamydia pneumoniae induces extensive changes in host cell gene expression. J Infect Dis 188:1310-1321

39. Wacher C, Muller M, Hofer MJ, Getts DR, Zabaras R, Ousman SS, Terenzi F, Sen GC, King NJ, Campbell IL (2007) Coordinated regulation and widespread cellular expression of interferon-stimulated genes (ISG) ISG-49, ISG-54, and ISG-56 in the central nervous system after infection with distinct viruses. J Virol 81:860 871

40. Woestyn S, Allaoui A, Wattiau P, Cornelis GR (1994) YscN, the putative energizer of the Yersinia Yop secretion machinery. J Bacteriol 6:1561-1569

41. Ying S, Seiffert BM, Hacker G, Fischer SF (2005) Broad degradation of proapoptotic proteins with the conserved Bcl-2 homology domain 3 during infection with Chlamydia trachomatis. Infect Immun 73:1399-1403

42. Zhong G, Fan T, Liu L (1999) Chlamydia inhibits interferon $\gamma$ inducible major histocompatibility complex class II expression by degradation of upstream stimulatory factor 1. J Exp Med 189:1931-1938

43. Zhong G, Liu L, Fan T, Fan P, Ji H (2000) Degradation of transcription factor RFX5 during the inhibition of both constitutive and interferon $\gamma$-inducible major histocompatibility complex class I expression in Chlamydia-infected cells. J Exp Med 191:15251534

44. Zhong G, Fan P, Ji H, Dong F, Huang Y (2001) Identification of a chlamydial protease-like activity factor responsible for the degradation of host transcription factors. J Exp Med 16:935-942 